\title{
The 3D Printing solutions during the COVID-19 pandemic in 2020/2021
}

\author{
H. Yaagoubi ${ }^{1 *}, H$. Abouchadi $^{1}$, M.TahaJanan ${ }^{1}$ \\ ${ }_{1}$ Laboratory of Applied Mechanics and Technologies (LAMAT), ENSET, STIS Research Center Mohammed V \\ University, Rabat, Morocco
}

\begin{abstract}
The 2019-2021 coronavirus pandemic (COVID-19), which began in the city of Wuhan in China, towards the end of 2019. As of March 12, 2020, the World Health Organization ordered the disease of coronavirus 2019 (COVID-19) as a pandemic, at the time of its composition, has spread to more than 180 countries on the planet. The number of COVID-19 patients is on the rise worldwide; given the high number of patients and the disruption of the production network; this has created a shortage of clinical parts and personal protective equipment; the $3 \mathrm{D}$ printing has endorsed its role in this area. $3 \mathrm{D}$ printing continues to provide healthcare workers with missing equipment for example, millions of face shields, face veils, valves, nasopharyngeal swabs and more have been made using $3 \mathrm{D}$ printing, in this article, we will share the contribution and experience of the $3 \mathrm{D}$ printing sector in the medical sector and a survey has been carried out of the studies to give a global view on the way and pace of use of this technology in the World during this health crisis.
\end{abstract}

\section{INTRODUCTION}

The 3D printing sector has mobilized to support the international effort, local and health authorities and the medical profession in the fight against the COVID-19 epidemic.After World Health Organization ordered that 2019 coronavirus disease (COVID-19) is declared a dangerous pandemic, and has quickly spread to all countries in the world has created a tragically stress and sensational effect on everybody's life. Until this year 2021 over $2,550,000$ individuals have encountered indications and more than 175,000 have passed on from respiratory and medical issues, Today, we see that $3 \mathrm{D}$ printing has been an essential tool in the medical sector this concept, is used in various fields such as health in order to respond quickly to increasing demand in means of prevention and fight against covid-19 [14], 3D printing allows small manufacturing units as well as universities to play a role in the fight against the epidemic, because the requirements for $3 \mathrm{D}$ printing are quite meager.3D printing enables us to test a lot of options. it's can be rapidly changing the plan if something is not working[5-11]. A large portion of these depends on open-source models for an equivalent STL project [12]. The only need is an online design file and one or two people to oversee production Most of the work can be done remotely. Production lines far and wide 
have been broken since the Covid-19 emergency started. Deficiency of covers, lack of ventilators, absence of specific medications...so, governments needed to discover new answers for adapting. Numerous beginners and expert craftsmen have gone to $3 \mathrm{D}$ printing to deliver objects essential for this wellbeing war. In only half a month, a huge number of things were printed, sparing lives and securing forefront labourerthe $3 \mathrm{D}$ printing sector aims to match the material needs of the hospital environment to existing 3D printing infrastructures», water and electricity supplies, are intended to relieve patient crowding and stress on the hospital's resources. This article introduces and talks about different kinds of arrangements created by AM during COVID-19 pandemic. The 3D printing sector is mobilizing to supply visor masks, this application emerged from an absence of individual defensive gear (EPIs) for those working in emergency clinics and wellbeing focuses,also HP \& Peak Sport Products mask adjusterin light of meeting with clinical staff working substantial hours during the coronavirus pandemic in China. It is a little part that can change a great deal. The component was intended for individuals working in clinics and research centres, who currently need to wear them for a considerable length of time. The substitution fastens of the Mask improves the solace of wearing it, permitting, among others to maintain a strategic distance from ear torment coming about because of the delayed weight of the elastics on the rear of the auricles [10].

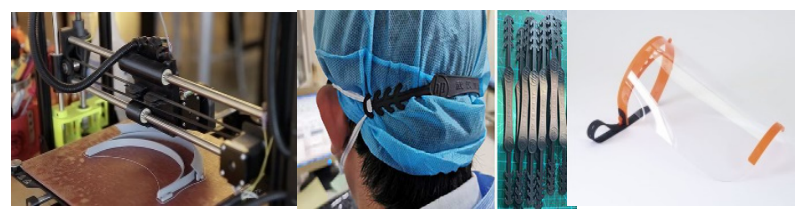

Fig1.Visor masks and mask adjuster [4]

Also, we have seen the manufacturing of respirator valves . When the Covid previously arrived in Europe, Italy was perhaps the most influenced nations. Numerous clinics were packed and needed sterile hardware expected to save the patients in the most extreme condition. After discovering that a medical clinic in Chiari had a lack of

ventilator valves, the Italian organization Issinova, assumed control over the issue. Understanding that $3 \mathrm{D}$ printing was the most productive arrangement, Issinova started to additively fabricate the essential measure of valves for the wellbeing places that required them. Afterwards, the producer Photocentric additionally dispatched large-scale manufacturing of respiratory valves for a few nations. On account of their sap machines and their high assembling speed, they had the option to grow more than of 40,000 valves for each week utilizing $3 \mathrm{D}$ printing. The main exploration was the italian examination which firms that empowered the crisis assembling of respirator valves for a medical clinic in Lombardy [5].Due to the lack of independent breathing apparatus, a few groups of specialists, in collaboration with various foundations and faculties of health, create models and produce the different breathing parts using 3D printing.Coronavirus patients may introduce SARS, with high respiratory rates and low oxygen levels. 


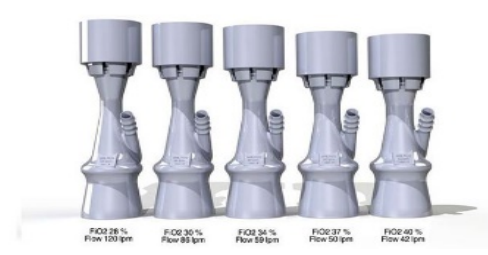

Fig.2 A Different variants of valve connectors made utilizing SLS/PA12 [5]

Toward the start of April, we got the news that a few organizations had utilized added substance assembling to deliver swabs for PCR tests. These swabs can be utilized as an instrument to gather tests of the nasal mucosa. When ,the example is gathered, the swab is checked for the presence of the infection. The velocity at which Covid-19 spread across the world brought about a mass lack of the swabs expected to play out these tests. Reacting to this lack the organization's Carbon and Formlabs, started to produce around 150'000 nasal swabs a day utilizing 3D tar printing. These swabs were fundamental to quickening the location of positive cases and consequently ruining the spread of the infection.

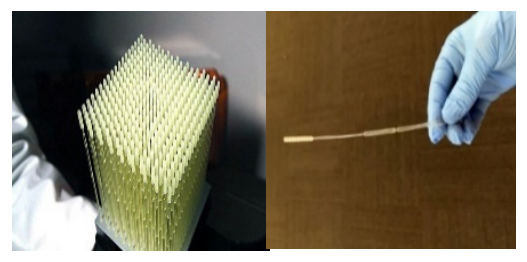

Fig.3 Nasal swabs [4]

Nonetheless, because COVID-19 can be communicated through safety glasses, an additional tool against covid19with solid contribution with clinical 3D printing, HuaXiang experts had the alternative to quickly make,

redesign and favour these protective glasses in just ten days, and promptly conveyed an enormous number of sets on farsoon 403p machines [9].

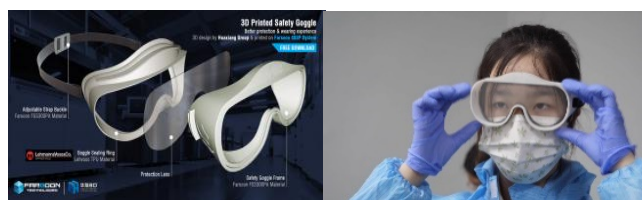

Fig.4Safety glasses [9]

You have doubtlessly as of now observed the well-known easy breath veil from the french brand decathlon on the seashores: the gadget was intended for swimming and covered the whole face while joining a snorkel to relax. In Italy, specialists have changed this wellknown cover into a respirator because of a valve imprinted in 3D: 500 italian patients have 
quite recently getting it! Be cautious be that as it may, decathlon determines that the veil ought not be adjusted without anyone else, this could have genuine outcomes on its working and its wind streams.

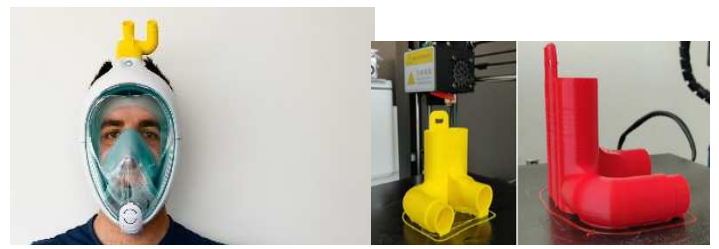

Fig.5Decathlon masks transformed into respirators thanks to 3D printing[7]

\section{SURVEY}

A survey was done to give a worldwide vision in transit and the pace of the utilization of this $3 \mathrm{D}$ printing technology on the planet during this wellbeing emergency and a few reactions from various nations has been gotten:

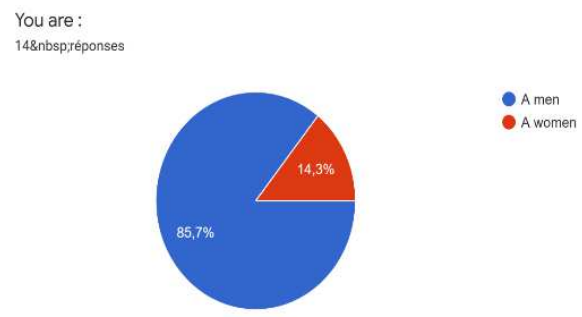

Fig.6 Response of question 1: You are?Gender:

The figure 6 shows the most of the users of 3D Printing who responded to this question 1 are $85,7 \%$ are the men and $14,3 \%$ are women.

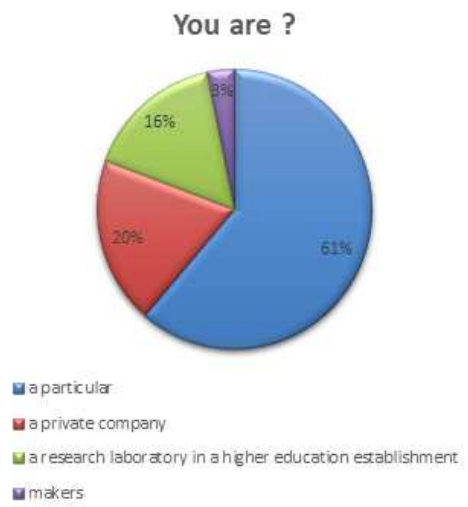

Fig.7Response of question 2: your career? 
The figure 7 shows $61 \%$ of the population which use 3D printing are particular in this period of confinement and $20 \%$ are a private company and $16 \%$ are a research laboratory in a higher education establishment and $3 \%$ are makers.

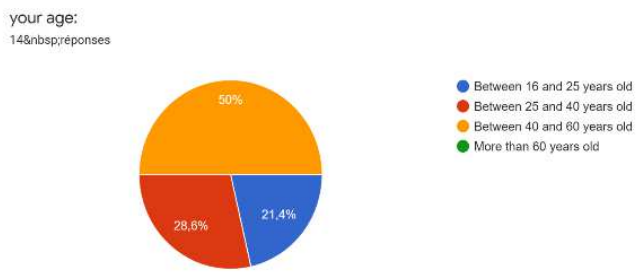

Fig.8Response of question 3: Your age?

Figure 8 shows the age of most of the users of 3D Printing who responded to this question 3 is $50 \%$ between 40 and 60 years old and $28,6 \%$ between 25 and 40 years old and $21,4 \%$ between 16 and 25 years old.

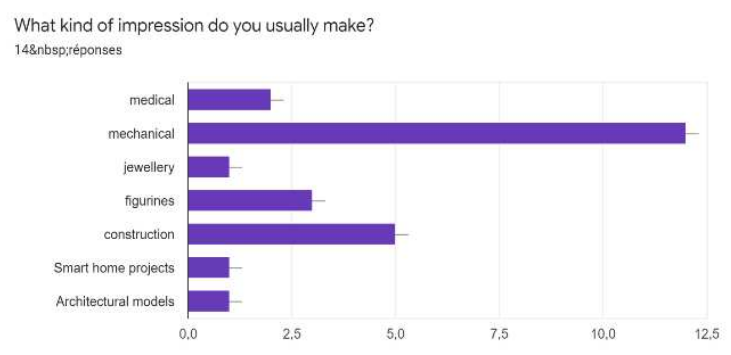

Fig.9Response of question 4: What kind of impression do you usually make?

Figure 9 shows that the kind of impression that the users usually make is, $85,7 \%$ for the mechanical field, $35,7 \%$ for construction, $21,4 \%$ for figurines, $14,3 \%$ medical,7,1\% jewellery, $7,1 \%$, smart home projects $7,1 \%$ architectural models.

In what context do you use 3D printing? / In which context do you use 3D printing? *

148nbsp,réponses

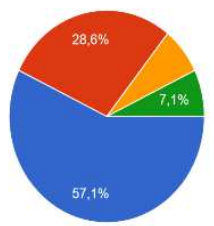

- Loisirs / hobby 
Fig.10Response of question 5:In what context do you use 3D printing? / in which context do you use $3 \mathrm{D}$ printing?

The figure 10 shows the context of the use of 3D printing ,57,1\% for hobby, $28,6 \%$ are professional, $7,1 \%$ are twice hobbies and pro.

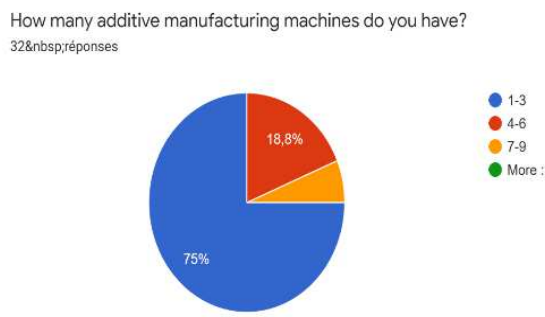

Fig.11Response of question 6: How many additive manufacturing machines do you have?

figure 11 shows the most users have 75\% between 1 and 3 machines and 18,8\% have between 4 and 6 machines and $7.1 \%$ have between 7 and 9 machines, $86 \%$ of users own between one and three machines, and 14\% own between four and six machines.

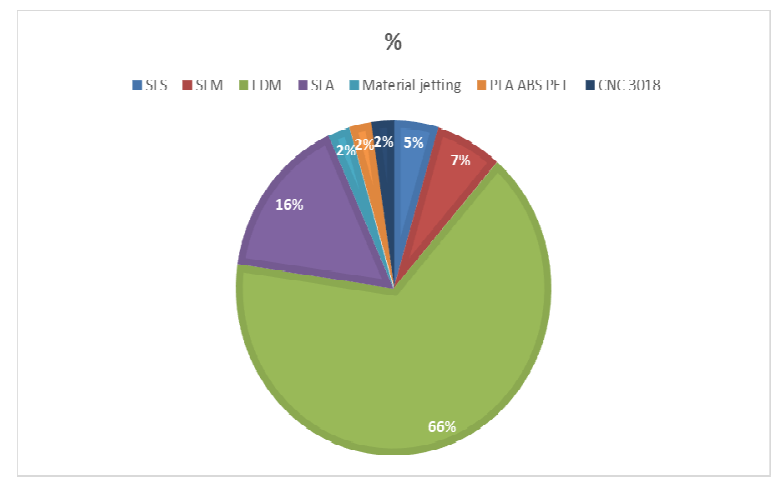

Fig.12Response of question 7: Specify the types of processes for your machines?

The figure 12 shows the most technology used in this confinement are the FDM (Fused Deposition Modeling) 66\%andSLA Stereolithography about 16\% and 7\% SLM and 5\% SLS2\% for PLA, CNC 3018. 


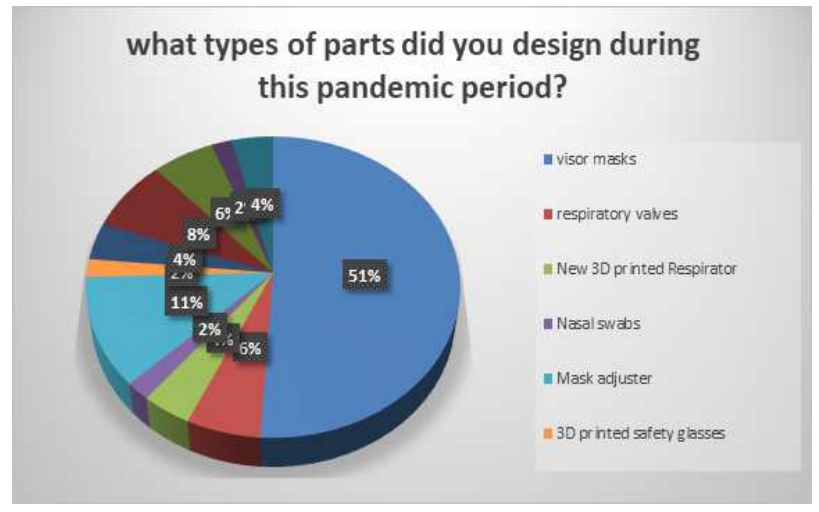

Fig.13Response of question 8: Have you designed pieces for vital applications in the context of the mobilization against covid19? what types of parts did you design during this pandemic period?

A lot of peoples produce $51 \%$ of visor masks, $8 \%$ of respirator valves and new 3D printed respirator invention, and also $11 \%$ mask adjuster ,3D printed safety glasses, nasal swabs.

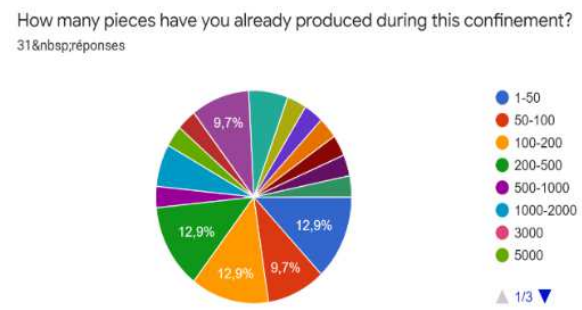

Fig 14.Response of question 9: How many pieces have you already produced during this confinement?

$12,9 \%$ of the users of $3 \mathrm{D}$ printing have already produced more than 100 or 500 pieces during the year 2020 .

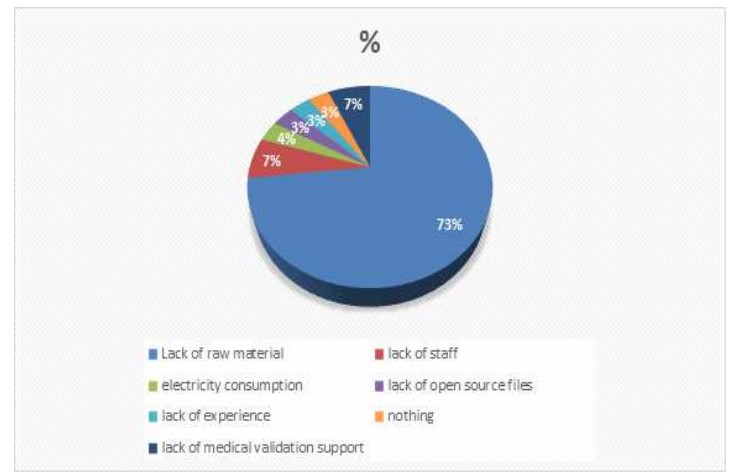


Fig.15Response of question 10: What kind of difficulties did you find?

The figure 15 show that the most workers suffer from the lack to raw material (about $73 \%$, and $7 \%$ lack of staff and 7\% lack of medical support validation and 3\% lack of open-source files, others problem like lack of rawmaterial, lack of staff, lack of medical validation support and $7 \%$ they found no difficulty.

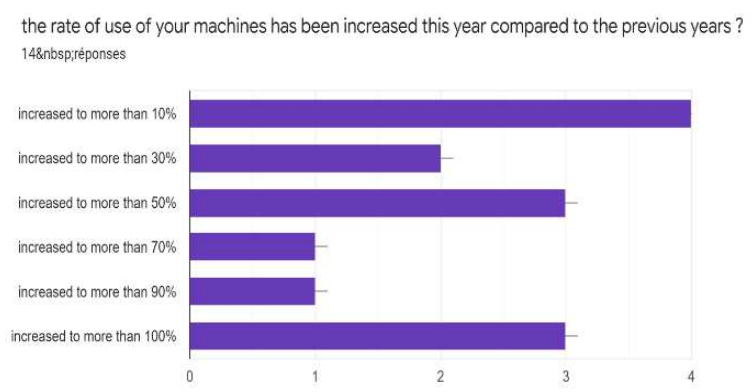

Fig.16Response of question 11:The rate of use of your machines has been increased this year compared to the previous years?

For $28,6 \%$ of peoples, the use of this machine increased for them more than $10 \%$ and $21,4 \%$ of others increased to more than $50 \%$, and we find other people $(21,4 \%)$ which increased to more than $100 \%$.

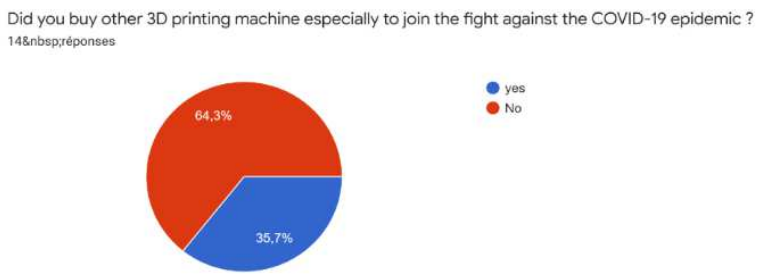

Fig.17Response of question 12:Did you buy other 3D printing machinesespecially to join the fight against the covid-19 epidemic?

$35,7 \%$ have buy other 3D Printing machine specially to join the fight against the covid-19 epidemic. 


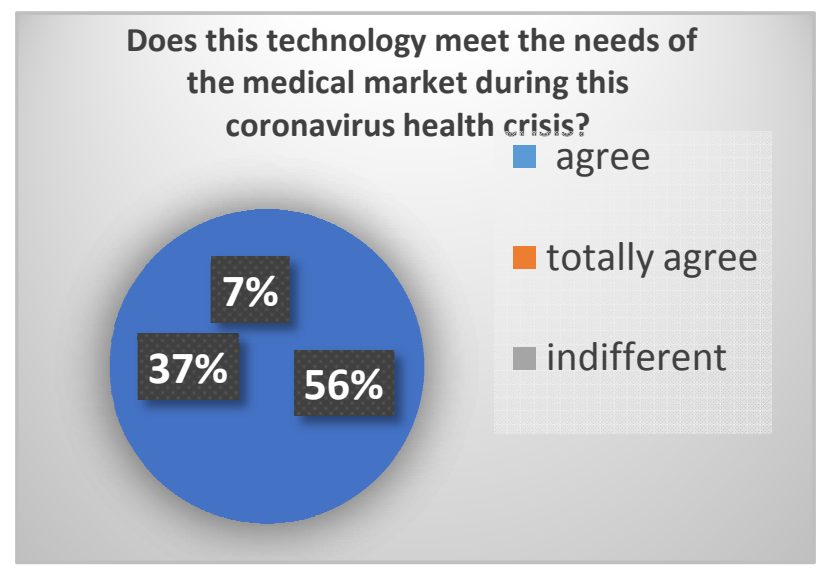

Fig.18Response of question 13: Does this technology meet the needs of the medical market during this coronavirus health crisis?

The result in the figure 18 show that $56,7 \%$ of users they agree that this technology meets the needs of the medical market during this coronavirus health crisis, and $37 \%$ alsoare totally agree and just $15 \%$ are indifferent with this idea.

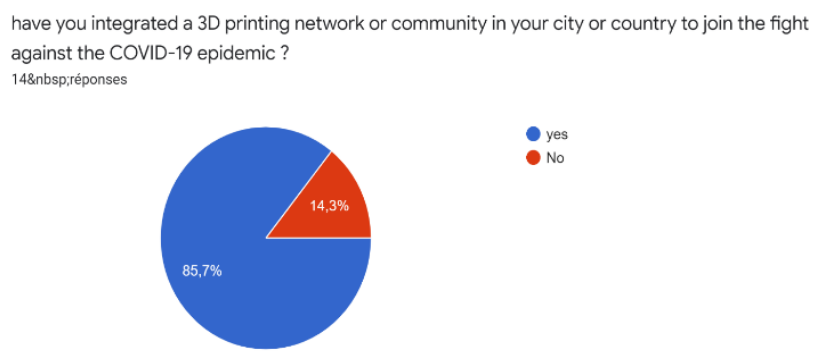

Fig.19Response of question 14: Have you integrated a 3D printing network or community in your city or country to join the fight against the covid-19 epidemic?

$85 \%$ have integrated a $3 \mathrm{D}$ printing network or community in their city or country as volunteer to join the fight against the covid-19 epidemic.

\section{CONCLUSIONS}

On the off chance that $3 \mathrm{D}$ printing has for quite some time been introduced as a genuine modern upset, we have never felt significant progress toward this path. However, the guarantee is incredible: anybody can have the option to print anything, without moving from their lounge chair. 3D printing has numerous focal points: prototyping is quicker, customization simpler and in the thought, anybody can have a $3 \mathrm{D}$ printer at home. Throughout the years, a few obstructions have eased back the advancement of this industry, prominently its gradualness and its expense, there is no uncertainty that flexibly chains have broken during regulation measures. One of the answers for these deficiencies is currently $3 \mathrm{D}$ printing. Tragically, we needed to sit tight for an occasion like this to 
demonstrate it. This period of pandemic shows the importance of this technology, by the contribution to the fight.

\section{REFERENCES}

[1] Wolfel R, Corman VM, Guggemos W, et al. Virological assessment of hospitalized patients with COVID2019. Nature 2020. https://doi.org/10.1038/s41586-020-2196-

[2] x. 3. Patel R, Babady E, Theel ES, et al. Report from the American Society for Microbiology COVID-19 international summit, 23 March 2020: Value of diagnostic testing for SARS-CoV-2/COVID-19. mBio 2020;11:e0722-20. 4. Mathew E, Domi'nguez-Robles

[3] J, Larran eta E, et al. Fused deposition modelling as a potential tool for antimicrobial dialysis catheters manufacturing: New trends vs. conventional approaches. Coatings 2019;9:

[4] https://www.3dhubs.com/blog/manufacturing-prusa-protective-face-shields-for-hospitals-in-denver-colorado/

[5]https://3dprint.com/266107/3d-printing-during-coronaviruspandemic-italian-doctor-creates-3d-printedconnectors-ventilators

[6]https://www.3dhubs.com/blog/manufacturing-prusa-protective-face-shields-for-hospitals-in-denver-colorado/

[7] https://www.3dnatives.com/en/3d-printed-respirator-250320205/

[8] https://filament2print.com/gb/blog/85_3D-printing-against-covid-19.html

[9] https://www.3dprintingmedia.network/forums/topic/huaxiang-group-safety-goggles-medically-validated/

[10] https://newsnetwork.mayoclinic.org/discussion/3d-anatomic-modeling-lab-printing-ear-loop-maskattachments-for-staff/

[11] https://3dadept.com/covid-19-spain-approves-first-medical-3d-printed-ventilator-next-step-is-to-produce-100ventilators-per-day

[12] https://copper3d.com/hconnector/ 